\title{
OBLIGATORIEDAD Y VINCULATORIEDAD DE LAS DECISIONES DE LA CORTE IDH EN EL DERECHO INTERNO ARGENTINO. HACIA UNA VERDADERA EFICACIA
}

* Profesor Adscrito de Derecho Constitucional 1, Facultad de Derecho, Universidad Nacional de Rosario de Argentina (UNR), Miembro del Instituto de Derecho Procesal Constitucional del Colegio de abogados de Rosario.

\section{INTRODUCCIÓN}

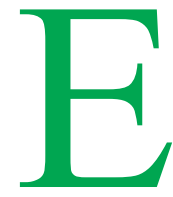

$\mathrm{n}$ una época pasada (mediados del siglo XX) fue indispensable para la conformación del Sistema Regional Americano de Derechos Humanos su configuración normológica (habida cuenta de que no era suficiente el reconocimiento de derechos individuales en las Constituciones de los Estados) y así entre otros antecedentes ${ }^{1}$ se firma el instrumento más importante como ser la CADH de fecha 22/11/1969 -aprobada en 1984 por Ley 23054 en Argentina y con rango constitucional desde 1994. EIIo configuró un primer paso en cuanto a la protección, promoción y defensa de los derechos fundamentales, pues se logró que ellos tengan una vigencia formal para los Estados Partes. Pero la actualidad del siglo XXI nos coloca ante un nuevo reto o desafío, que es la eficacia real de aquellas normas, principios y valores otrora concebidos: es el problema del ejercicio de las normas internacionales (sean éstas consuetudinarias -eje: ius cogens-, ó convencionales) en el plano de la realidad social interna del Estado.
Es por ello que éste trabajo se focalizará primero en el estudio de la actividad de los órganos que tienenporcompetencia elresguardodelasnormas de la CADH, a fin de precisar la naturaleza y alcance de sus decisiones, con el afán de evitar interpretaciones obsoletas e inconvenientes al respecto. En segundo lugar mostraremos cómo realmente se están ejecutando las sentencias de la Corte IDH en Argentina, poniendo de realce la falta de cumplimiento por los órganos del poder local de sus obligaciones internacionales en plazos razonables. Pero en especial, haremos referencia a la jurisprudencia de nuestra CSJN (Corte Suprema de Justicia de la Nación) sobre el tema, como así también a la jurisprudencia de la Corte IDH.

En éste contexto ponderando la necesaria articulación de la labor de los tribunales supranacionales con los tribunales nacionales y la protección del mismo objeto en común que son los derechos fundamentales, se buscará ofrecer algunas propuestas, de corte legislativo (como, nuevamente, el reclamo por la sanción de un Código Procesal Constitucional Federal), trayendo a colación experiencias comparadas.

1 En cuanto a los antecedentes de la CADH, véase LAVIÑA, Félix, "Sistemas Internacionales de Protección de los Derechos Humanos”, Editorial Depalma. Año 1987, página 67 y ss. 
Se verificará, que gran parte del problema de la ejecución de las sentencias y/o directivas de la Corte IDH y de la Comisión IDH, pasa por la falta de "voluntad política" al respecto, la burocratización, todo lo que configura una verdadera inconstitucionalidad por omisión, ya que las normas de la $\mathrm{CADH}$ tienen rango constitucional, y no obstante que se hallen formalmente vigentes, la ineficiencia por falta de ejercicio en el plano fáctico de la realidad social, genera responsabilidad internacional del Estado Argentino.

\section{LAS DECISIONES DE LA CORTE IDH}

La Corte Interamericana de Derechos Humanos fue establecida como consecuencia de haber entrado en vigor el 18 de julio de 1978, la CADH ó "Pacto de San José de Costa Rica" al ser depositado el undécimo instrumento de ratificación. Tiene por función asegurar el cumplimiento de las obligaciones impuestas por la Convención, ejerciendo funciones contenciosa y consultiva. La primera se refiere a la resolución de casos sometidos por la Comisión IDH o un Estado Parte, donde se ha alegado que uno de los Estados miembros ha violado la Convención. Dentro de esta función la Corte tiene la facultad de dictar medidas provisionales de protección. La segunda función se refiere a la facultad que tienen los Estados partes de consultar a la Corte IDH acerca de la "interpretación" de la CADH o de otros tratados concernientes a la protección de los derechos fundamentales en los Estados Americanos. También podrán consultarla, en lo que les compete, los órganos de la OEA señalados en su Carta.

El problema aparece en cuanto a la determinación del "alcance y proyección" de las decisiones de la Corte IDH en el ámbito interno del país, en cuanto a si son obligatorias en todos los casos, o sólo en algunos, o si son vinculantes sirviendo como una pauta de orientación o guía para el juez nacional. Ello naturalmente repercute en torno a su "ejecución", no existiendo unanimidad de criterios al respecto. En éste marco, a renglón seguido estudiaremos a cada hipótesis.

\section{1) En ejercicio de la FUNCIÓN CONTENCIOSA:}

Por esta vía, la Corte determina si un Estado ha incurrido en responsabilidad internacional por la violación de alguno de los derechos consagrados en la $\mathrm{CADH}$, esto es, haber incumplido con sus obligaciones de respetar y garantizar tales derechos. La competencia contenciosa del Tribunal se encuentra regulada en el artículo 62.1 de la de la CADH la cual dispone: "Todo Estado parte puede, en el momento del depósito de su instrumento de ratificación o adhesión de esta Convención, o en cualquier momento posterior, declarar que reconoce como obligatoria de pleno derecho y sin convención especial la competencia de la Corte sobre todos los casos relativos a la interpretación o aplicación de esta Convención".

El artículo 63.1 de la CADH incluye la siguiente disposición concerniente a los fallos de la Corte: "Cuando decida que hubo violación de un derecho o libertad protegidos en esta Convención, la Corte dispondrá que se garantice al lesionado en el goce de su derecho o libertad conculcados. Dispondrá así mismo, si ello fuera procedente, que se repare las consecuencias de la medida o situación que ha configurado la vulneración de esos derechos y el pago de una justa indemnización a la parte lesionada".

El artículo 68.1 de la CADH determina que "los Estados parte en la Convención se comprometen a cumplir la decisión de la Corte en todo caso que sean parte".

El artículo 68.2 de la CADH dispone que "la parte del fallo que disponga indemnización compensatoria se podrá ejecutar en el respectivo país por el procedimiento interno vigente para la ejecución de sentencias contra el Estado". 
Los fallos del Tribunal son "definitivos e inapelables". En caso de desacuerdo sobre el sentido o alcance del fallo, la Corte lo interpretará a solicitud de cualquiera de las partes, siempre que dicha solicitud se presente dentro de los noventa días a partir de la fecha de la notificación del fallo (art. $67 \mathrm{CADH}$ ).

Durante el año $2006^{2}$ se sometieron a consideración de la Corte 17 casos contenciosos y ésta emitió 23 sentencias. En 3 de ellas se pronunció sobre excepciones preliminares, de fondo, reparaciones y costas, conjuntamente; en 14 acerca del fondo y las correspondientes reparaciones; y en 6 en torno a la interpretación de sentencias. La Corte somete a la Asamblea General en cada periodo ordinario de sesiones un informe sobre su labor, en el cual de manera especial y con las recomendaciones pertinentes, señalará los casos en que un Estado no haya dado cumplimiento a sus fallos (art. $65 \mathrm{CADH}$ ).

Veintiún (21) Estados Parte han reconocido la competencia contenciosa de la Corte, ellos son: Costa Rica, Perú, Venezuela, Honduras, Ecuador, Argentina, Uruguay, Colombia, Guatemala, Suriname, Panamá, Chile, Nicaragua, Paraguay, Bolivia, El Salvador, Haití. Brasil, México, República Dominicana y Barbados.

Ahora bien, fijado el marco normativo, corresponde determinar cuándo la sentencia de la Corte IDH es "obligatoria" y cuando es "vinculante". El profesor Osvaldo Gozaini ${ }^{3}$ sostiene la postura de que si el Estado Argentino es "parte" en un proceso ante la Corte IDH la sentencia será obligatoria, pero si no lo es la jurisprudencia de la Corte IDH sentada en un caso contencioso será vinculante (no obligatoria) en la medida que el Estado Argentino ha aceptado la competencia supranacional, sirviendo el precedente como una guía o pauta de interpretación a seguir por el juez nacional.

La CSJN en la causa "Videla Jorge R"4 sostuvo que a partir de la reforma de 1994 a la CN (art.
75 inc.22) se otorga jerarquía constitucional a la CADH, razón por la cual la jurisprudencia de la Corte IDH en causas en las que son parte otros Estados miembros de la convención, constituyen una insoslayable pauta de interpretación para los poderes constituidos argentinos en el ámbito de sus competencias, y en consecuencia también para la CSJN, a los efectos de resguardar las obligaciones asumidas por el Estado argentino en el sistema interamericano de protección de los derechos humanos.

\section{2) En ejercicio de la FUNCIÓN DE CONSULTA:}

Por este medio, la Corte responde consultas que formulan los Estados miembros de la OEA o los órganos de la misma, en los términos del artículo 64 de la Convención que dispone:

1. Los Estados miembros de la Organización podrán consultar a la Corte acerca de la interpretación de esta Convención o de otros tratados concernientes a la protección de los derechos humanos en los Estados americanos. Asimismo, podrán consultarla, en lo que les compete, los órganos enumerados en el Capítulo X de la Carta de la Organización de los Estados americanos, reformada por el Protocolo de Buenos Aires.

2. La Corte, a solicitud de un estado miembro de la Organización, podrá darle opiniones acerca de la compatibilidad entre cualquiera de sus leyes internas y los mencionados instrumentos internacionales.

El derecho de solicitar una opinión consultiva no se limita a los Estados partes en la Convención; todo Estado miembro de la OEA tiene capacidad de solicitarla. Los Estados miembros de la Organización son: Antigua y Barbuda, Argentina, Bahamas, Barbados, Belice, Bolivia, Brasil, Canadá, Colombia,

2 Conf. Corte IDH, Informe año 2006, último publicado en: http://www.corteidh.or.cr/informes.cfm

3 GOZAINI, Osvaldo A. "Incidencia de la Sentencia de la Corte Interamericana de Derechos Humanos en el Derecho Interno" Revista de Estudios Constitucionales, año 4, No. 2, Universidad de Talca, Año 2006, Pág. 354 y ss.

4 Voto de Maqueda., CSJN, Fallo del 21/08/2003, publicado en LL, 2003-F-87. 
Costa Rica, Chile, Dominica, Ecuador, El Salvador, Estados Unidos, Grenada, Guatemala, Guyana, Haití, Honduras, Jamaica, México, Nicaragua, Panamá, Paraguay, Perú, República Dominicana, Saint Kitts y Nevis, Santa Lucía, San Vicente y las Granadinas, Suriname, Trinidad y Tobago, Uruguay y Venezuela.

Igualmente, la competencia consultiva de la Corte fortalece la capacidad de la Organización para resolver los asuntos que surjan por la aplicación de la Convención, ya que permite a los órganos de la OEA consultar a la Corte, en lo que les compete.

Ahora bien, y siguiendo nuevamente la opinión de Osvaldo Gozaini ${ }^{5}$, cuando la Corte IDH ejerce su jurisdicción interpretativa de consulta, la jurisprudencia será obligatoria para el Estado Argentino, Y para todos los Estados Miembros, por la razón de que se está interpretando al "sistema" de derechos humanos y tal como lo ha dicho la Corte IDH en la opinión consultiva $\mathrm{N}^{\circ} 15 / 97^{6}$ el Estado u órgano que solicita una opinión consultiva no es el único titular de un interés legítimo en el resultado del procedimiento, razón por la cual su desistimiento al pedido no reviste carácter vinculante para la Corte IDH que puede continuar con la tramitación del asunto.

No obstante se hace una aclaración, en el sentido de que si la normativa interna es suficiente o más extensa en la protección del derecho humano que la normativa internacional, regirá ésta por aplicación del principio pro homine?

También debemos tener presente que ésta no es una opinión unánime, ya que algunos autores sostienen que las decisiones de la Corte IDH en ejercicio de su jurisdicción de consulta podrán ser "vinculantes" pero no "obligatorias".

\section{3) En la toma de MEDIDAS PROVISIONALES:}

La Corte IDH puede adoptar las medidas que considere pertinentes en casos de extrema gravedad y urgencia, y cuando se haga necesario evitar daños irreparables a las personas, tanto en casos que estén en conocimiento de la Corte, como en asuntos que aún no se han sometido a su conocimiento, a solicitud de la Comisión Interamericana. El artículo 63.2 de la Convención señala que:

"En casos de extrema gravedad y urgencia, y cuando se haga necesario evitar daños irreparables a las personas, la Corte, en los asuntos que esté conociendo, podrá tomar las medidas provisionales que considere pertinentes. Si se tratare de asuntos que aún no estén sometidos a su conocimiento, podrá actuar a solicitud de la Comisión".

Durante el año 2006 fueron sometidas a consideración de la Corte 13 solicitudes de medidas provisionales, de las cuales cuatro fueron rechazadas y nueve fueron adoptadas ${ }^{9}$. En cuanto al Estado argentino, la Corte IDH tiene registradas a lo largo de su labor las siguientes medidas provisionales: Caso Buenos Aires respecto Argentina, Asunto de las Penitenciarías de Mendoza respecto Argentina, Asunto Millacura Llaipén y otros respecto Argentina, Asunto Reggiardo Tolosa respecto Argentina.

5 GOZAINI, Oswaldo A. Op. Cit., Pág. 355.

6 Corte IDH, Opinión Consultiva $N^{\circ}$ 15/97, de fecha 14/11/97, publicada en LL, 1998-E-496.

7 PINTO, Mónica, "El principio pro homine. Criterios de hermenéutica y pautas para la regulación de los derechos humanos", en Abregú, Martin y Courtis, Christian [compiladores]: La aplicación de los tratados sobre derechos humanos por los tribunales locales, Centro de Estudios Legales y Sociales, Editores del Puerto, Buenos Aires, 1997, p. 163.

8 GONZÁLEZ, Boris Barrios., "La cosa Juzgada nacional y el cumplimiento y ejecución de las sentencias de la Corte Interamericana de Derechos Humanos por los Estados Partes”, Revista de Estudios constitucionales Año $4 N^{\circ} 2$, Universidad de Talca, Año 2006, Pág.374.

9 Conf. Corte IDH, Informe Año 2006 Pág. 5, publicado en : http://www.corteidh.or.cr/informe.cfm 
Con Trinidad y Tobago tiene la Corte IDH y la OEA el primer caso de "rebeldía" al ventilarse el caso James y otros: donde justamente no se acató las "medidas provisionales" fijadas por la Corte IDH.

Como puede colegirse, el problema de la eficacia en el plano interno de los Estados Partes de las decisiones del alto tribunal supranacional, no sólo se refiere a la faceta contenciosa (en cuanto al fondo del asunto ventilado) y la consultiva, sino también a la cautelar.

\section{2) LAS RECOMENDACIONES E INFORMES DE LA COMISIÓN IDH ¿SON OBLIGATORIAS?}

Recordemos que según la $\mathrm{CADH}$ (art.33) la Comisión IDH es uno de los órganos competentes de protección de los derechos fundamentales en el sistema, si bien no tiene técnicamente naturaleza jurisdiccional $^{10}$, y por ello alguna doctrina la define como un órgano administrativo ${ }^{11}$, $u$ otros autores como un órgano cuasi-jurisdiccional ${ }^{12}$. Lo cierto es que ella no se integra de "jueces" sino de "miembros", cuales tienen por misión importante elaborar informes y recomendaciones de acuerdo al art.41 de la CADH.

De esta forma, lo que en éste punto nos proponemos averiguar es si las directivas de la Comisión IDH son obligatorias ó sólo meramente vinculantes, como un consejo a seguirse. Para ello sintetizaremos la jurisprudencia al respecto, tanto de la Corte IDH como la de nuestra CSJN.
El alto tribunal supranacional, en una primer etapa emite dos sentencias "Caballero Delgado y Santana c/ Colombia" (24/12/92) y "Genie Lacayo c/ Nicaragua" (27/01/07), donde se dijo que las "recomendaciones" no contaban con obligatoriedad porque solamente seinterpretaban "conforme su sentido corriente", aplicando la regla de interpretación contenida en el artículo 31.1 de la Convención de Viena sobre el Derecho de los Tratados. En otra etapa, registrada a partir del caso "Loayza Tamayo c/ Perú (17/09/97), aplicó el principio de buena fe de la Convención de Viena, expresando que si un Estado suscribe y ratifica un tratado internacional, especialmente si es de derechos humanos, tiene la obligación de realizar sus mejores esfuerzos para aplicar las recomendaciones.

Respecto de nuestra CSJN, sin olvidar por su puesto la importancia de los precedentes "Ekmekdjian c/ Sofovích" y "Giroldi", fue específicamente en la causa "Bramajo"13 donde la Corte Nacional le adjudicó la calidad de: "guía para la interpretación de los preceptos convencionales a la opinión de la Comisión IDH', en la medida en que el Estado argentino reconoció la competencia de ésta para conocer en todos los casos relativos a la interpretación y la aplicación de la $\mathrm{CADH}$ (consid. $8^{\circ}$ del voto de la mayoría).

Pero se verificó un importante "retroceso"14 jurisprudencial en la causa "Acosta"15, donde aclaró que, si bien por el principio de buena fe que rige la actuación del Estado argentino en el cumplimiento de sus compromisos internacionales, éste "debe realizar los mejores esfuerzos para dar respuesta favorable a las recomendaciones efectuadas por la Comisión IDH, ello no equivale a consagrar como deber para los jueces el de dar cumplimiento a su

10 GOZAINI, Oswaldo A. Op. Cit. Pág. 357.

11 LAVIÑA, Félix., Op. Cit. Pág. 107.

12 BAZÁN, Víctor., "La Interacción del Derecho Internacional de los Derechos Humanos y el Derecho Interno en Argentina”, Revista de Estudios constitucionales, Año 5, $N^{\circ} 2$, Universidad de Talca, Año 2007, Pág. 172.

13 Fallos 319: 1840. Del 12/09/1996

14 Conf. LOIANNO, Adelina., "Incidencia de la Jurisprudencia de la Corte Interamericana y de las recomendaciones de la Comisión en el Derecho Interno", en "Derechos Humanos", Editorial Fundación de Derecho Administrativo, $5^{\circ}$ Edición Bs. As., Año 2005 , pp III $-17-y$ ss.

15 Fallos 321: 3555. Del 22/12/98. 
contenido, al no tratarse aquéllas de decisiones vinculantes para el Poder Judicial"' (consid. 13 de la mayoría).

En verdad y como sostiene la doctrina ${ }^{16}$ lo que la CSJN ha querido dejar en claro, es la bifurcación de criterios, manteniendo su posición en torno a la inoperatividad de los decisorios de la Corte IDH y paralelamente inclinarse por la no obligatoriedad de los pronunciamientos de la Comisión IDH, que comenzó a moldear en "Acosta". La visión jurídica sentada en "Acosta", fue confirmada en "Felícetti"17, causa vinculada con el públicamente conocido copamiento de La Tablada (ver consid. $6^{\circ}$ de la mayoría), y en la causa "Alonso" 18 (consid. $5^{\circ}$ del voto mayoritario).

Sin embargo, en el caso "Simón"", la CSJN (consid. 17 de la mayoría) ha catalogado a la jurisprudencia de la Corte IDH y a las directivas (informes y recomendaciones) de la Comisión IDH como "una imprescindible pauta de interpretación de los deberes y obligaciones derivados de la CADH", lo cual refleja una revalorización de los pronunciamientos de la Comisión.

Pero no obstante que "Simón" pueda leerse como el comienzo del fin de tal dualidad apuntada, la doctrina citada piensa que no se ha llegado aún al ideal que consagre la obligatoriedad de los pronunciamientos de la Comisión IDH y no sólo que se vea en ellos su magnitud como parámetros hermenéuticos.

Sólo resta esperar que se consolide y luego evolucione, la tendencia que la Corte Nacional recomenzará a escribir en "Simón", retornando - aunque con mayores precisión terminológica y densidad jurídica - la huella dejada en "Bramajo".

\section{PROCEDIMIENTOS DE EJECUCIÓN DE LA SENTENCIA DE LA CORTE IDH:}

Talcomolohabríamosseñaladoenlaintroducción a éste trabajo, en el siglo XXI el desafío que se propone para los Estados Miembros del sistema regional interamericano, es el de efectivizar el ejercicio de los derechos fundamentales que ya se han obligado a respetar formalmente en sus ámbitos internos.

Para ello, es inexorable el cumplimiento, acatamiento y ejecución en el derecho interno de las sentencias de la Corte IDH, pues como lo sostiene la doctrina ${ }^{20}$, tal jurisprudencia es "definitiva e inapelable", hace cosa juzgada formal y material, y deviene ejecutoria para el Estado condenado.

No obstante tal circunstancia, en el plano de la realidad social sucede algo distinto, pues se registran varios casos de incumplimiento de las decisiones de la Corte IDH, lo que se calificó por la doctrina ${ }^{21}$ como casos de "rebeldía", por ejemplo: el primer caso de contumacia se registró por el Estado Parte de Trinidad y Tobago en la causa "James y otros", donde la Comisión IDH había solicitado una medida provisional en cuanto a la protección de la vida de 5 personas condenadas a muerte, medida otorgada por la Corte y no acatada por el país en cuestión. El Estado miembro de Perú también fue remiso a ejecutar la sentencia de la Corte IDH en las causas "Loaiza Tamayo" y "Castillo Petruzzi", la que declaró "inejecutables". También el Estado de Panamá, en el caso: "Baena Ricardo y Otros", fue rebelde en torno a la posibilidad de que la Corte IDH pueda "supervisar" el

16 BAZÁN, Víctor. Op. Cit. Pág. 169.

17 Fallos 323: 4130, del 21/12/00.

18 Fallos 325: 2322, del 19/09/02.

19 Fallos 328: 2056, del 14/06/05.

20 AYALA CORAO, Carlos M. "La Ejecución de sentencias de la Corte Interamericana de Derechos Humanos", Estudios Constitucionales, año 5, $N^{\circ} 1$, Centro de Estudios Constitucionales, Universidad de Talca, Santiago de Chile, 2007, Pág. 134

21 GONZÁLEZ, Boris Barrios., "La Cosa Juzgada Nacional y el cumplimiento y ejecución de las sentencias de la Corte Interamericana de Derechos Humanos por los Estados Partes”, Revista de estudios Constitucionales, Año 4, $N^{\circ} 2$, Universidad de Talca, Año 2006, Pág. 376. 
cumplimiento de la sentencia que había dictado objetándole tal facultad.

Entonces es necesario advertir, que para apuntar al logro de la efectivización de los derechos fundamentales en el ámbito interno, es necesario contar con una firme voluntad política al respecto $^{22}$, una adecuada legislación procesal constitucional que fusione y articule la tarea de los tribunales supranacionales con los tribunales nacionales, evitando la burocratización, y acatando las decisiones en plazos razonables.

Es por ello que, (apuntando la idea de Víctor Bazán), voluntad política mediante, sería útil que existiera una normativa que de modo claro paute el procedimiento para cumplir las recomendaciones de la Comisión IDH y las sentencias de la Corte IDH, al modo como existe mutatis mutandi en Costa Rica, en el "Convenio de sede entre el Gobierno de la República de Costa Rica y la Corte IDH", de 10 de septiembre de 1981, ratificado por Ley 6.889; Colombia, por medio de la Ley 288, de 5 de julio de 1996, y el Decreto 321, de 25 de febrero de 2000 y Perú art. 115 del Código de Procesal Constitucional -aprobado por Ley 28.237, publicada el 31 de mayo de 2004- y la Ley 27.775, publicada el 7 de julio de 2002. En sentido convergente, resulta altamente positivo el proyecto chileno de "Acciones protectoras de derechos fundamentales" -en debate en la Comisión de Derechos Humanos, Nacionalidad y Ciudadanía de la Cámara de Diputados de la Nación al mes de octubre de 2007-, se contemple específicamente en su art. 128, párrafo $1^{\circ}$, que las "sentencias de la Corte Internacional o supranacional en materia de derechos humanos a la que el Estado de Chile le haya reconocido jurisdicción contenciosa vinculante son de obligatorio cumplimiento por los órganos del Estado de Chile".

A renglón seguido, expondremos cómo en la realidad se "procede" a la efectivización de una sentencia de la Corte IDH, con particular referencia al Estado Argentino.

\section{1) La Supervisión:}

En aras de supervisar el cumplimiento del compromiso contraído por los Estados de "cumplir la decisión de la Corte en todo caso en que sean partes" (art 68 de la CADH), y en particular de informar a la Asamblea General los casos en que "un Estado no haya dado cumplimiento a sus fallos" (art. 65 de la CADH), la Corte IDH primero debe conocer el grado de cumplimiento de sus decisiones.

Para ello el Tribunal debe supervisar que los Estados responsables efectivamente cumplan con las reparaciones ordenadas por el Tribunal, antes de informar sobre el incumplimiento de una decisión a la Asamblea General de la OEA.

La supervisión sobre el cumplimiento de las resoluciones de la Corte implica, en primer término, que ésta solicite información al Estado sobre las actividades desarrolladas para los efectos de dicho cumplimiento, así como recabar las observaciones de la Comisión y de las víctimas o sus representantes. Una vez que el Tribunal cuenta con esa información puede apreciar si hubo cumplimiento de lo resuelto, orientar las acciones del Estado para este fin y cumplir con la obligación de informar a la Asamblea General, en los términos del art. 65 de la CADH.

De ésta forma, la Corte IDH no vuelve a dictar una nueva "sentencia" para cumplir una anterior, sino que emite una "resolución" (post-sentencia), en la que el único objeto será efectivizar lo decidido, a través del procedimiento descrito (Informe del Estado condenado-Observaciones de la Comisión y de la Víctima-Resolución de la Corte).

Tener presente que en virtud del carácter definitivo e inapelable de las sentencias de la Corte IDH, según lo establecido en el art. 67 de la $\mathrm{CADH}$, éstas deben ser prontamente cumplidas por el Estado en forma íntegra, (léase en plazos razonables). La obligación de cumplir 
lo dispuesto en las sentencias del Tribunal corresponde a un principio básico del derecho de la responsabilidad internacional del Estado, respaldado por la jurisprudencia internacional, según el cual los Estados deben acatar sus obligaciones convencionales internacionales de buena fe (pacta sunt servanda) y, como lo dispone el art 27 de la Convención de Viena sobre el Derecho de los Tratados de 1969, los Estados no pueden, por razones de orden interno, dejar de asumir la responsabilidad internacional ya establecida. Las obligaciones convencionales de los Estados Partes vinculan a todos los órganos del Estado (Poder Ejecutivo Nacional, Poder Legislativo Nacional, Poder Judicial Nacional).

Los Estados Partes de la CADH deben garantizar el cumplimiento de las disposiciones convencionales y sus efectos propios (effet utile) en el plano de sus respectivos derechos internos. Este principio se aplica no sólo en relación con las normas sustantivas de los tratados de derechos humanos (es decir, las que contienen disposiciones sobre los derechos protegidos), sino también en relación con las normas procesales, tales como las que se refieren al cumplimiento de las decisiones de la Corte IDH. Estas obligaciones deben ser interpretadas y aplicadas de manera que la garantía protegida sea verdaderamente práctica y eficaz, teniendo presente la naturaleza especial de los tratados de derechos humanos.

En particular referencia al Estado argentino, la Corte IDH ha emitido 5 resoluciones de supervisión de sentencia ${ }^{23}$, en las causas: Caso Garrido y Baigorria Vs. Argentina (en 2 oportunidades), Caso Cantos Vs. Argentina (en 2 oportunidades), y el Caso Bulacio Vs. Argentina. Respecto de las mismas, en los puntos siguientes de éste trabajo analizaremos cómo nuestro país incurrió en inconstitucionalidad por omisión, al no efectivizar a través de los órganos del poder competentes, normas de rango constitucional (art. 75 inc. $22 \mathrm{CN}$ ), burocratizando el procedimiento de ejecución en plazos irrazonables.

\section{2) La Presentación de INFORMES:}

Hemos señalado supra que a los fines de efectivizar lo decidido por la Corte IDH, se impulsa un procedimiento que comienza con un informe del Estado condenado-, continúa con las Observaciones de la Comisión y de la Víctima y finaliza con una Resolución de la Corte.

Que los Estados Partes en la CADH en la medida que han reconocido la jurisdicción obligatoria de la Corte IDH, tienen el deber de acatar las obligaciones establecidas por el Tribunal. Esta obligación entonces incluye el deber del Estado condenado de informar a la Corte sobre las medidas adoptadas para dar cumplimiento a lo ordenado por el Tribunal en la Sentencia, así como en la Resolución. La oportuna observancia de la obligación estatal de indicar al Tribunal cómo está cumpliendo cada uno de los puntos ordenados por éste es fundamental para evaluar el estado del cumplimiento del caso. Asimismo, la Asamblea General de la OEA ha reiterado que, con el propósito de que el Tribunal pueda cumplir cabalmente con la obligación de informarle sobre el cumplimiento de sus fallos, es necesario que los Estados Parte le brinden oportunamente la información que aquélla les requiera.

El deber de informar a la Corte no se cumple con la sola presentación formal de un documento ante el Tribunal, sino que constituye una obligación de carácter dual que requiere para su efectivo cumplimiento la presentación formal de un documento en plazo y la referencia material específica material específica, actual, cierta y detallada a los temas sobre los cuales recae dicha obligación.

Por ejemplo en la causa "Cantos Vs. Argentina" (28/11/02) la Corte IDH sentenció que el Estado argentino violó el derecho de acceso a la justicia consagrado en los artículos 8.1 y 25 de la $\mathrm{CADH}$, en relación con el art. 1.1 de la misma, en perjuicio del señor José María Cantos. En este marco se dictaron posteriormente 2 resoluciones de 
supervisión, siendo la última de fecha 12/07/07 donde Argentina informó lo siguiente: que el $25 \mathrm{de}$ enero de 2006 el Poder Ejecutivo Nacional dictó el Decreto $\mathrm{N}^{\circ}$ 99/06 que sometió a consideración del Congreso de la Nación argentino un proyecto de Ley cuyo texto ordenaba dar cumplimiento a lo resuello por el punto $1^{\circ}$ del párrafo $77 \mathrm{de}$ la sentencia emitida por la Corte IDH en el caso CANTOS-CDH 11.636 con fecha 28 de noviembre de 2002, y que el 10 de mayo de 2007 la Procuración del Tesoro de la Nación solicitó al Ministerio de Justicia y Derechos Humanos, por ser éste órgano el responsable de las medidas requeridas por la Corte Interamericana, un informe sobre "las medidas tomadas y/o proyectadas particularmente respecto al cumplimiento de los puntos resolutivos primero, segundo, tercero y cuarto de la sentencia de la Corte IDH,

Pero no sólo se "informa" a través de comunicados el Estado condenado, sino que también lo hace la Comisión IDH y la víctima a través de sus representantes legales. Así, y en cuanto refiere al caso "Cantos", la Comisión informó lo siguiente: "queobservacon preocupación elincumplimiento de la casi totalidad de las medidas de reparación ordenadas por el "Tribunal" y que "el Estado no haya ofrecido información alguna respecto a los avances que pudieran haberse producido en el curso de los últimos dos años en relación con el cumplimiento de lo ordenado por el Tribunal", y "que solicita a la Corte que requiera al Estado informar con precisión cuál es el cronograma y cuáles son los plazos previstos para concretizar las medidas previstas por el Poder Ejecutivo que siguen pendientes".

Frente a tales "informes" el tribunal resolvió de manera contundente y clara diciendo: "que al supervisar el cumplimiento integral de la Sentencia en el presente caso, y después de analizar la información aportada por el Estado argentino la Comisión IDH y los representantes de la víctima en sus escritos sobre el cumplimiento de la Sentencia, la Corte observa que el Poder Ejecutivo de Argentina, mediante la sanción del Decreto 99/06 y la remisión de un proyecto de ley al Poder Legislativo Nacional, ha adoptado medidas tendientes a dar pleno cumplimiento a los puntos resolutivos pendientes de la Sentencia de 28 de noviembre de 2002, mas no ha cumplido con dichas obligaciones de manera "concreta".

\section{3) Inexistencia de PLAZOS RAZONABLES de ejecución:}

Siguiendo al ejemplo testigo que hemos tomado para nuestro país (o sea, la causa "Cantos"), la sentencia sobre el fondo fue dictada por la Corte IDH en fecha 28/11/02, supervisada por primera vez en cuanto a su cumplimiento en fecha 28/11/05 y nuevamente en fecha 12/07/07, donde la Corte IDH después de ponderar los informes y las observaciones, manifiesta literalmente lo siguiente: ... "Que a más de cuatro años y medio de haberse dictado la Sentencia de 28 de noviembre de 2002, hay una falta de cumplimiento de cuatro de la cinco medidas de reparación ordenadas por el Tribunal en dicha Sentencia".

Ello lleva a reflexionar acerca de la eficacia del sistema interamericano y del real ejercicio de las normas fundamentales que se propone proteger en el plano interno de los Estados Partes. El hecho de que para la victima de la violación de un derecho humano tenga que pasar casi 5 años para que se cumpla una de las cinco medidas que ordenó un Tribunal Supranacional no es indiferente.

Pero el problema puede ser aún mayor, pues tal como lo acotamos más arriba, existen precedentes depaíses "rebeldes" al acatamiento de las decisiones de la Corte IDH (tal como sucedió con Trinidad y Tobago, Perú y Panamá) que directamente llegaron a manifestar que incumplirían tales pronunciamientos. Volviendo a la Argentina, en el caso "Garrido y Baigorria", la Corte IDH dicta sentencia sobre el fondo de la cuestión en fecha 2/2/96 y respecto de las reparaciones en fecha 27/8/98. La última resolución de supervisión es la del 27/11/07, en la cual la Corte ponderó el 
informe de la Comisión IDH que justamente puso de realce el transcurso de 9 años desde la sentencia de reparaciones y 17 años desde la comisión del hecho y en concreto no se resolvió el caso.

Entonces, es indispensable como venimos sosteniendo a lo largo de éste trabajo, y a los fines de que se cumplan y ejecuten los pronunciamientos de la Corte IDH en plazos razonables, la articulación de la labor de los tribunales supranacionales con los tribunales nacionales a través de una adecuada legislación procesal constitucional federal, acompañada de una seria voluntad política al respecto, evitando la burocratización del procedimiento de su ejecución, logrando así o al menos anhelando la efectivización del ejercicio de los derechos fundamentales.

\section{JURISPRUDENCIA DE LA CORTE IDH EN REFERENCIA A LA ARGENTINA:}

En éste punto, nos proponemos hacer una simple reseña de los casos que de acuerdo a los registros publicados por la Corte IDH en su sitio oficial ${ }^{24}$, se encuentra vinculado el Estado Argentino como potencial violador de normas fundamentales de derechos humanos.

Para ello, discriminaremos entre: a) Casos Contenciosos. b) Opiniones Consultivas, c) Medidas Provisionales, d) Supervisión de Cumplimiento de Sentencias.

\section{A) Casos Contenciosos:}

Corte IDH. Caso Maqueda Vs. Argentina. Excepciones Preliminares. Resolución de 17 de enero de 1995. Serie C No. 18.

Corte IDH. Caso Garrido y Baigorria Vs.
Argentina. Fondo. Sentencia de 2 de febrero de 1996. Serie C No. 26.

Corte IDH. Caso Garrido y Baigorria Vs. Argentina. Reparaciones y Costas. Sentencia de 27 de agosto de 1998. Serie C No. 39.

Corte IDH. Caso Cantos Vs. Argentina. Excepciones Preliminares. Sentencia de 7 de septiembre de 2001. Serie C No. 85.

Corte IDH. Caso Cantos Vs. Argentina. Fondo, Reparaciones y Costas. Sentencia de 28 de Noviembre de 2002. Serie C No. 97.

Corte IDH. Caso Bulacio Vs. Argentina. Fondo, Reparaciones y Costas. Sentencia de 18 de Septiembre de 2003. Serie C No. 100.

Corte IDH. Caso Bueno Alves Vs. Argentina. Fondo, Reparaciones y Costas. Sentencia de 11 de mayo de 2007. Serie C No. 164.

\section{B) Opiniones Consultivas:}

Corte IDH. Ciertas Atribuciones de la Comisión Interamericana de Derechos Humanos (arts. 41, 42, 44, 46, 47,50 Y 51 Convención Americana sobre Derechos Humanos). Opinión Consultiva OC.13/93 del 16 de julio de 1993. Serie A No. 13

C) Medidas Provisionales:

Corte IDH. Asunto Reggiardo Tolosa respecto Argentina

Resolución de la Corte 19-01-94

Resolución de la Corte 19·11-93

Corte IDH. Asunto Millacura Llaipén y otros respecto Argentina 
Resolución de la Corte 21-06-06

Resolución de la Corte 06-07-06

Resolución de la Corte 06-02-08

Corte IDH. Asunto de las Penitenciarias de Mendoza respecto Argentina

Resolución dé la Corte 22-11-04

Resolución de la Corte 18-06-05

Resolución de la Corte 30-03-06

Resolución de la Corte 22-08-07

Resolución de la Corte 27-11-07

Corte IDH. Caso Bueno Alves respecto Argentina

Resolución de la Corte 02-02-07

D) Supervisión de Cumplimiento de sentencias:

Corte IDH. Caso Garrido y Baigorria Vs. Argentina. Supervisión de Cumplimiento de Sentencia. Resolución de la Corte Interamericana de Derechos Humanos de 17 de Noviembre de 2004.

Corte 1DH. Caso Bulacio Vs. Argentina. Supervisión de Cumplimiento de Sentencia. Resolución de la Corte Interamericana de Derechos Humanos de 17 de noviembre de 2004.

Corte IDH. Caso Cantos Vs. Argentina. Supervisión de Cumplimiento de Sentencia. Resolución de la Corte Interamericana de Derechos Humanos de 28 de noviembre de 2005.

Corte IDH. Caso Cantos Vs. Argentina. Supervisión de Cumplimiento de Sentencia. Resolución de la Corte de 12 de julio de 2007.
Corte IDH. Caso Garrido Y Baigorria VI. Argentina. Supervisión de Cumplimiento de Sentencia. Resolución de la Corte Interamericana de Derechos Humanos de 27 de noviembre de 2007.

\section{JURISPRUDENCIA DE LA CSJN SOBRE EL TEMA}

Ahora nos toca realizar un breve pasaje en cuanto a la interpretación judicial del máximo tribunal de justicia argentino, en cuanto respecta al acatamiento o no de los pronunciamientos de la Comisión IDH y la Corte IDH.

A) "Ekmekdjian c/ Sofovích" 25 (del 7 de julio de 1992), la CSJN tomó en su fallo la hermenéutica que la Corte IDH realizó respecto de la $\mathrm{CADH}$, sosteniendo precisamente que la interpretación de ésta debe guiarse por la jurisprudencia del Tribunal interamericano, para pasar a citar aprobatoriamente la Opinión Consultiva (OC) 7/8689 (ver consid. 21 y ss. de la mayoría), en la que la Corte IDH interpretó el art. 14.1 del Pacto.

B) "Giroldi"26 (del 7 de abril de 1995) en el que la CSJN sostuvo que la expresión "en las condiciones de su vigencia", bajo la que adquiere jerarquía constitucional la $\mathrm{CADH}$ (art. 75, inc. 22, párr. $2^{\circ}$ ), significa el modo como ella rige en el ámbito internacional y "considerando particularmente su efectiva aplicación jurisprudencial por los tribunales internacionales competentes para su interpretación y aplicación. De ahí que la aludida jurisprudencia deba servir de guía para la interpretación de los preceptos 
convencionales en la medida en que el Estado argentino reconoció la competencia de la Corte IDH para conocer en todos los casos relativos a la interpretación y aplicación de la CADH, (arts. 75, de la C.N., 62 y 64 de la CADH, y 2 de la ley 23.054). En el considerando n ${ }^{\circ} 12$ la CSJN manifestó: "A ésta Corte le corresponde en la medida de su jurisdicción aplicar los tratados internacionales ya que de lo contrario podría implicar responsabilidad de la Nación frente a la comunidad internacional".

C) "Bramajo"27 (del 12 de septiembre de 1996), la CSJN le adjudicó la calidad de "guía para la interpretación de los preceptos convencionales a la opinión de la Comisión IDH", en la medida en que el Estado argentino reconoció la competencia de ésta para conocer en todos los casos relativos a la interpretación y la aplicación de la CADH (consid. $8^{\circ}$ del voto de la mayoría).

D) "Acosta"28 (del 22 de diciembre de 1998), Aquí se registra un "retroceso" en la jurisprudencia de la CSJN, en cuanto refiere al valor acordado a las directivas de la Comisión IDH, al decir: "Si bien por el principio de buena fe que rige la actuación del Estado argentino en el cumplimiento de sus compromisos internacionales, éste debe realizar los mejores esfuerzos para dar respuesta favorable a las recomendaciones efectuadas por la Comisión, ello no equivale a consagrar como deber para los jueces el de dar cumplimiento a su contenido, al no tratarse aquéllas de decisiones vinculantes para el Poder Judicial" (consid. 13 de la mayoría).
E) “Cantos"29 (del 21 de agosto de 2003), aquí la CSJN desestimó por mayoría una presentación del Procurador General del Tesoro que pretendía que el Tribunal diera cumplimiento a una sentencia de la Corte IDH que había declarado que el Estado argentino violó normas de la CADH. El Tribunal declinó la intervención requerida, aduciendo que un temperamento contrario importaría infringir cláusulas de raigambre constitucional cuya titularidad corresponde a diversos profesionales que actuaron en la causa "C.1099.XX, 'Cantos, José María c/ Santiago del Estero, Provincia de y/o Estado Nacional s/ cobro de pesos",, con patente y deliberada renuncia de su más alta y trascendente atribución, para cuyo ejercicio ha sido Instituida como titular del PJN, que es ser el custodio e intérprete final de la C.N. (consid. $3^{\circ}$ de la mayoría). Además, sostuvo que, "bajo el ropaje de dar cumplimiento con una obligación emanada de un tratado con jerarquía constitucional (art. 63.1, de la $\mathrm{CADH}$ ), llevaría a la inicua -cuanto paradójica- situación, de hacer incurrir al Estado argentino en responsabilidad internacional por afectar garantías y derechos reconocidos a los profesionales, precisamente, en el instrumento cuyo acatamiento se invoca" (consid. $4^{\circ}$ del voto mayoritario).

F) "Expósito"30 (del 23 de diciembre 2004), la CSJN retorna una postura demostrativa de su permeabilidad para acatar los pronunciamientos del Tribunal consedeen Costa Rica, al admitir mayoritariamente el recurso extraordinario deducido contra una sentencia que había declarado 
extinta la acción penal por prescripción en una causa abierta por hechos que luego fueron juzgados por dicha Corte IDH, cuyas decisiones -sostuvo la CSJNresultan de "cumplimiento obligatorio para el Estado argentino (art. 68.1, CADH)", por lo cual también ella, en principio, debe subordinar el contenido de sus decisiones a las de dicho tribunal internacional (consid. $6^{\circ}$ de la mayoría).

G) "Arancibia Calvel"31 y "Simón"32, (del 24 de agosto de 2004 Y 14 de junio de 2005 respectivamente), son una buena muestra del nivel de acatamiento de los fallos de la Corte IDH, donde las respectivas posturas mayoritarias siguieron muy de cerca a un pronunciamiento fundamental de la jurisprudencia interamericana: el nombrado "caso Barrios Altos". Fundamentalmente, le proporcionaron útiles aportes de hermenéutica y aplicación jurídica las consideraciones sobre la inadmisibilidad de las disposiciones de amnistía, de prescripción y el establecimiento de excluyentes de responsabilidad "que pretendan impedir la investigación y sanción de los responsables de las violaciones graves de los derechos humanos tales como la tortura, las ejecuciones sumarias, extralegales o arbitrarías y las desapariciones forzadas, todas ellas prohibidas por contravenir derechos inderogables reconocidos por el Derecho Internacional de los Derechos Humanos".

\section{CONCLUSIONES}

1) $\mathrm{La}$ Corte IDH ejerce funciones contenciosa y consultiva. El problema aparece en cuanto a la determinación del "alcance y proyección" de las decisiones de la Corte IDH en el ámbito interno del país, en cuanto a si son obligatorias en todos los casos, ó sólo en algunos, ó si son vinculantes sirviendo como una pauta de orientación ó guía para el juez nacional. Ello naturalmente repercute en tomo a su “ejecución”, no existiendo unanimidad de criterios al respecto.

2) Respecto de la jurisdicción contenciosa de la Corte IDH, cuando el Estado argentino es "parte", la sentencia será obligatoria, pero si no lo es, la jurisprudencia de la Corte IDH sentada en un caso será vinculante (no obligatoria) en la medida en que el Estado argentino haya aceptado la competencia supranacional, sirviendo el precedente como una guía o pauta de interpretación a seguir por el juez nacional.

3) Cuando la Corte IDH ejerce su jurisdicción de consulta, la jurisprudencia será obligatoria para el Estado argentino, y para todos los Estados Miembros, por la razón de que se está interpretando al "sistema" de derechos humanos. No obstante se hace una aclaración, en el sentido de que si la normativa interna es suficiente o más extensa en la protección del derecho humano que la normativa internacional, regirá ésta por aplicación del principio pro homine.

4) La Corte IDH puede adoptar las medidas provisionales que considere pertinentes en casos de extrema gravedad y urgencia. Por lo tanto también el problema de la eficacia en el plano interno de los Estados parte de las decisiones del alto tribunal supranacional, no solo se refiere a la faceta contenciosa (en cuanto al fondo 
del asunto ventilado) y la consultiva, sino también a la cautelar.

5) En el siglo XXI el desafío que se propone para los Estados Miembros del sistema regional interamericano, es el de efectivizar el ejercicio de los derechos fundamentales que ya se han obligado a respetar formalmente en sus ámbitos internos. Para ello, es inexorable el cumplimiento, acatamiento y ejecución en el derecho interno de las sentencias de la Corte IDH, pues tal jurisprudencia es "definitiva e inapelable", hace transito a cosa juzgada formal y material, y deviene ejecutoria para el Estado condenado.

6) En el plano de la realidad social se registran varios casos de incumplimiento de las decisiones de la Corte IDH, lo que se calificó como casos de "rebeldía". Entonces es necesario advertir, que para apuntar al logro de la efectivización de los derechos fundamentales en el ámbito interno, es necesario contar con una firme voluntad política al respecto, una adecuada legislación procesal constitucional que fusione y articule la tarea de los tribunales supranacionales con los tribunales nacionales, evitando la burocratización y acatando las decisiones en plazos razonables.

7) La supervisión sobre el cumplimiento de las resoluciones de la Corte implica, en primer término, que ésta solicite información al Estado sobre las actividades desarrolladas para los efectos de dicho cumplimiento, así como recabar las observaciones de la Comisión y de las víctimas o sus representantes. Una vez que el Tribunal cuenta con esa información puede apreciar si hubo cumplimiento de lo resuelto, orientar las acciones del Estado para este fin y cumplir con la obligación de informar a la Asamblea General, en los términos del art. 65 de la $\mathrm{CADH}$.

8) En particular referencia al Estado argentino la Corte IDH ha emitido 5 resoluciones de supervisión de sentencia, en las causas: caso Garrido y Baigorria Vs. Argentina (en 2 oportunidades), Caso Cantos Vs. Argentina (en 2 oportunidades), y el Caso Bulacio Vs. Argentina. Respecto de las mismas nuestro país incurrió en inconstitucionalidad por omisión, al no efectivizar a través de los órganos del poder competentes, normas de rango constitucional (art 75 inc.22 $\mathrm{CN}$ ), burocratizando el procedimiento de ejecución en plazos irrazonables.

9) En síntesis, es indispensable (como lo venimos sosteniendo) que se cumplan y ejecuten los pronunciamientos de la Corte IDH en plazos razonables, articulando la labor de los tribunales supranacionales con los tribunales nacionales a través de una adecuada legislación procesal constitucional federal, acompañada de una voluntad política al respecto, evitando la burocratización del procedimiento de su ejecución, logrando así el efectivo ejercicio do los derechos fundamentales del ser humano.

\section{BIBLIOGRAFÍA}

AYALA CORAO, Carlos M. "La ejecución de sentencias de la Corte Interamericana de Derechos Humanos", Estudios Constitucionales, año 5, $\mathrm{N}^{\circ} 1$, Centro de Estudios Constitucionales, Universidad de Talca, Santiago de Chile, 2007, Pág. 134

BAZÁN, Víctor. "La Interacción del Derecho Internacional de los Derechos Humanos y el Derecho Interno en Argentina", Revista de Estudios Constitucionales, Año 5, $\mathrm{N}^{\circ} 2$, Universidad de Talca, 2007, Pág. 172 
GONZÁLEZ, Boris Barrios. "La Cosa Juzgada Nacional y el cumplimiento y ejecución de las sentencias de la Corte Interamericana de Derechos Humanos por los Estados Partes", Revista de Estudios Constitucionales, Año 4, N², Universidad de Talca, 2006, Pág. 376.

GOZAINI, Osvaldo A. "Incidencia de la Sentencia de la Corte Interamericana de Derechos Humanos en el Derecho Interno" Revista de Estudios Constitucionales, Año 4, $\mathrm{N}^{\circ}$ 2, Universidad de Talca, 2006, Pág. 354 y

ss.

LOIANNO, Adelina. "Incidencia de la Jurisprudencia de la Corte Interamericana y de las recomendaciones de la Comisión en el Derecho Interno", en "Derecho Humanos", Editorial Fundación de Derecho Administrativo, $5^{\circ}$ Edición Bs. As. 2005, Pág. III - 17 y ss.

PINTO, Mónica. "El principio pro homine. Criterios de hermenéutica y pautas para la regulación de los derechos humanos", en Abregú, Martín y Courtis, Christian (compiladores): La aplicación de los tratados sobre derechos humanos por los tribunales locales, Centro de Estudios Legales y Sociales, Editores del Puerto, Buenos Aires, 1997, Pág. 163. 